\title{
Uncertainties in the application of the species area relationship for characterisation factors of land occupation in life cycle assessment
}

\author{
An M. De Schryver • Mark J. Goedkoop • \\ Rob S. E. W. Leuven • Mark A. J. Huijbregts
}

Received: 4 October 2009 /Accepted: 1 June 2010 /Published online: 18 June 2010

(C) The Author(s) 2010. This article is published with open access at Springerlink.com

\begin{abstract}
Purpose Uncertainties in land use damage modeling are recognized, but hardly quantified in life cycle assessment (LCA). The objective of this study is to analyze the influence of various key assumptions and uncertainties within the development of characterisation factors (CFs) for land use in LCA. We assessed the influence on land use CFs of (1) parameter uncertainty and (2) the choice for a constant or land use-specific species accumulation factor $\mathrm{z}$ and including or excluding regional effects.

Methods A model framework was developed to analyze the uncertainties of CFs for six land use types and three agricultural practices. The CFs are expressed as potential disappeared fraction (PDF) of vascular plant species based on the species area relationship $\left(S=\mathrm{c} . \mathrm{A}^{\mathrm{z}}\right)$. The species area relationship describes the relation between the species number and area size, with help of the species accumulation factor $\mathrm{z}$ and the species richness factor c. A dataset representative for Great Britain was used to quantify both modeling choices and parameter uncertainty. Modeling choices were analyzed by defining three coherent scenarios, based on cultural theory perspectives. The parameter
\end{abstract}

Electronic supplementary material The online version of this article (doi:10.1007/s11367-010-0205-2) contains supplementary material, which is available to authorized users.

A. M. De Schryver $(\bowtie) \cdot$ R. S. E. W. Leuven • M. A. J. Huijbregts Radboud University Nijmegen,

Institute for Water and Wetland Research,

Department of Environmental Science,

Heyendaalseweg,

1356525 AJ Nijmegen, The Netherlands

e-mail: an.schryver@gmail.com

M. J. Goedkoop

PRé Consultants bv,

Amersfoort, The Netherlands uncertainties of average species number and species accumulation factor $\mathrm{z}$ were quantified using Monte Carlo simulation.

Results and discussion Pair-wise comparison of the CFs shows that $68-85 \%$ of the CFs significantly differ from each other within each perspective. It is found that the ranking of organic, less intensive, and intensive land practices of each land use type is unaltered by the chosen model scenario. However, the absolute values of the CFs can change from negative to positive scores with an average difference of 0.8 PDF between the two extreme perspectives, i.e., individualistic and egalitarian. The difference between these scenarios is for $40 \%$ explained by the choice in $\mathrm{z}$ and for $60 \%$ by the choice in including regional effects. Within the egalitarian and hierarchist perspective the species accumulation factor $\mathrm{z}$ is for more than $80 \%$ responsible for the parameter uncertainty.

Conclusions Modeling choices and uncertainties within the species area relationship hardly change the ranking of the different land practices but largely influence the absolute value of the CFs for land use. The absolute change in the land use CFs can change the interpretation of land use impacts compared with other stressors such as climate change.

Keywords Biodiversity - Land use - Life cycle assessment . Perspectives · Species area relationship - Uncertainty analysis

\section{Introduction and objective}

Human land use activities are one of the dominant stressors for terrestrial species. Currently, $24 \%$ of the earth terrestrial 
surface is occupied by cultivated systems including cropland and grassland used to produce food, feed, and fiber (FAO 2000; Sarukhán et al. 2005). By the year 2100, land use change is projected to have the largest global impact on species richness (Sala et al. 2000).

The impact of land use activities is also an important element to consider in the life cycle assessment (LCA) of products. Within the framework of LCA, the effects of land use can be divided in three conceptual activities: transformation, occupation, and restoration of land (Milà i Canals et al. 2007a, b). Land occupation is defined as the use of a certain area for human activities such as storing materials or waste and production of agricultural products or resources, while land transformation and restoration are described as the processes which require transforming one land type into another (Muller-Wenk 1998). As a consequence of occupying or transforming land surfaces, ecosystems are modified in a way that is generally judged as damaging, such as loss of biodiversity or reduction in soil quality. For each activity, characterisation factors $(\mathrm{CFs})$ can be calculated based on a chosen quality indicator that describes the potential damage to the ecosystem. Milà i Canals et al. (2007a, b) present a list of possible quality indicators that cover most direct and indirect effects of land use. Soil quality (Baitz et al. 1998; Mattsson et al. 2000; Oberholzer et al. 2006; Milà i Canals et al. 2007a,b; Bos and Wittstock 2008), scaling (Sleeswijk et al. 1996; Jeanneret et al. 2006), and thermodynamic (Wagendorp et al. 2006) indicators work well for the comparison of different land use activities but do not provide the possibility to compare the environmental impact of land use with other terrestrial ecosystem-related impacts, such as acidification or eutrophication.

Aggregation across impact categories can be done by using indicators positioned at the end of the cause-effect chain. For ecosystem damage, Muller-Wenk (1998) proposes the potentially disappeared fraction (PDF) of species as endpoint indicator. This indicator measures the change in species diversity and is integrated over a certain time and area presented by the life cycle inventory. This approach is further developed and implemented by using the species area relationship with the species richness factor c and species accumulation factor $\mathrm{z}\left(S=\mathrm{c}^{*} \mathrm{~A}^{\mathrm{z}}\right)$ for land occupation and transformation (Koellner 2000; Koellner and Scholz 2007; Koellner and Scholz 2008; Schmidt 2008). Koellner and Scholz (2008) provide uncertainty estimates for CFs caused by empirical variation in the species richness data and limited sample size (parameter uncertainty). They also compare the results of a linear and non-linear calculation model (model uncertainty) and analyze the differences in results between the species groups plants, threatened plants, moss, and mollusks (choice uncertainty). Koellner and Scholz (2008) and Schmidt (2008) use a constant $z$ value of 0.21 or 0.23 to calculate CFs for land use. However, the value of the species accumulation factor $\mathrm{z}$ is widely discussed (Rosenzweig 1995; Crawley and Harral 2001; Collins et al. 2002) and depends on the type of habitat (Hannus and von Numers 2008; Kallimanis et al. 2008), the taxa (Humphreys and Kitchener 1982; Collins et al. 2002), and the size of the area (Lomolino 2001; Crawley and Harral 2001; Losos and Schluter 2000; Kallimanis et al. 2008; Harner and Harper 1976). A range of land use type and spatial scale specific $z$ values are published (Crawley and Harral 2001; Manhoudt et al. 2005; Dolnik and Breuer 2008).

The objective of this study is to analyze various key assumption and uncertainties in the species area relationship and how they influence the CFs for land occupation. We focus on the influence due to applying a constant or a variable species accumulation factor $\mathrm{z}$ and the choice of including or excluding regional effects. Furthermore, we assess the parameter uncertainties caused by the uncertainty in the species accumulation factor $\mathrm{z}$ and in the average species number using Monte Carlo simulation. The CFs are expressed as PDF of vascular plant species. Three types of management practices of cropland, fertile grassland, infertile grassland, tall grassland, moorland, and woodland are analyzed using the data of Countryside Survey 2000 (Defra 2000). Results are presented for three scenarios, quantifying the influence of coherent sets of value choices in the modeling procedure. These scenarios include the choice for (1) species accumulation factor $\mathrm{z}$ and (2) including or excluding regional effects.

\section{Methodology}

\subsection{Model approach}

\subsubsection{Framework}

The paper focuses on occupation of land. Land occupation causes a change in species richness within the occupied area compared with the baseline land (Milà i Canals et al. 2007a,b). The baseline to which we measured the actual damage of land use activities was chosen to be the species richness on the type of land that will arise without human distortion (Koellner, 2000; Vogtlander et al. 2004). Within continental Europe, this is forest for $80-90 \%$ of the land (Stanners and Philippe, 1995). During the occupation of land, two effects are observed:

1. The land quality on the occupied area itself changes, defined as local damage; 
2. The area size of surrounding baseline area and the occupying land use type changes, described as regional damage.

The total damage score can be defined as:

$\mathrm{DS}_{\mathrm{tot}, i}=\mathrm{DS}_{\mathrm{loc}, i}+\mathrm{DS}_{\mathrm{reg}, i}$

with $\mathrm{DS}_{\mathrm{tot}, i}, \mathrm{DS}_{\mathrm{loc}, i}$, and $\mathrm{DS}_{\mathrm{reg}, i}$ the total, local, and regional damage score $\left(\mathrm{PDF} \cdot \mathrm{m}^{2} \cdot\right.$ year) due to occupation with land use type $i$. The relative change in species richness for the local and regional situation can be calculated as:

$\mathrm{DS}_{i}=\mathrm{CF}_{i} \cdot A \cdot t_{i}$

where $\mathrm{CF}_{i}$ stands for the $\mathrm{CF}$ of land use type $i$; and $A_{i} t_{i}$ the area occupied (square meters) multiplied with the time of occupation by land use type $i$ (years), as collected in life cycle inventories. In our study, the CF to assess the environmental damage of land use is the PDF of species (Goedkoop and Spriensma 1999; Koellner and Scholz, 2007), which is calculated by:

$\mathrm{CF}_{i}=\frac{\Delta S}{S_{\mathrm{b}}}=\frac{S_{\mathrm{b}}-S_{i}}{S_{\mathrm{b}}}=1-\frac{S_{i}}{S_{\mathrm{b}}}$

with $S_{\mathrm{b}}$ the species number on the baseline land use type and $S_{i}$ the species number on the occupied land use type $i$ (unit less). The species number can be estimated by the species area relationship (Rosenzweig, 1995; MacArthur and Wilson, 1967). This relationship is described as:

$S=c \cdot A^{z}$

where $S$ represents the species number (unit less), $A$ the size of the area (square meters), $c$ the species richness factor, and $z$ the species accumulation factor.

\subsubsection{Local damage}

The local damage describes the change in species richness on the occupied area compared with the species richness on the baseline land. Implementing Eq. (4) into Eq. (3) gives the local $\mathrm{CF}\left(\mathrm{CF}_{\text {loc }, i}\right)$ :

$\mathrm{CF}_{\mathrm{loc}, i}=1-\frac{S_{i, 1}}{S_{\mathrm{b}, 1}}=1-\frac{C_{i}}{C_{\mathrm{b}}} \cdot A_{\mathrm{o}}^{z_{i, 1}-z_{\mathrm{b}, 1}}$

with $A_{\mathrm{o}}$ the new area occupied (square meters), $c_{\mathrm{b}}$ and $c_{i}$, the species richness factor of the baseline land use type and land use type $i, z_{\mathrm{b}, 1}$, and $z_{i, 1}$ the species accumulation factor of the baseline land use type and land use type $i$ on the local scale 1 .

\subsubsection{Regional damage}

The regional damage describes the marginal species change outside the occupied area. Occupying part of the baseline land can reduce the species richness in the region defined as the surrounding baseline area which can be occupied with other land use types, but in our case is assumed to be forest area (regional effect I). Next to this, when the area occupied with land use type $i$ gets connected with already existing land of the same type, the area of land use type $i$ is enlarged (regional effect II) and may create a rise in species number on land use type $i$. The regional damage score for land use type $i$, considering both effects, is given by:

$\mathrm{DS}_{\text {reg }, i}=\mathrm{DS}_{\text {regI }}+\mathrm{DS}_{\text {regII }}$

with $\mathrm{DS}_{\text {regI }}$ and $\mathrm{DS}_{\text {regII }}$ the damage scores for regional effects I and II. The marginal species loss for regional effect I is:

$\Delta S_{\mathrm{b}, r} \approx A_{\mathrm{o}} \cdot z_{\mathrm{b}, r} \cdot c_{\mathrm{b}} \cdot A_{r}^{z_{\mathrm{b}, \mathrm{r}}-1}$

where $A_{r}$ stands for the size of the surrounded region (square meters), $c_{\mathrm{b}}$ the species richness factor of the baseline land use type and $z_{\mathrm{b}, r}$ the species accumulation factor of the baseline land use type with area size $A_{r}-A_{\mathrm{o}} \approx A_{r}$ (square meters). More details can be found in the Supporting Information. Integrating Eq. (7) into Eq. (2), but reformulated for regional damage score $\left(\mathrm{DS}_{\text {regI }}\right)$, equals to:

$\mathrm{DS}_{\mathrm{regl}}=A_{\mathrm{o}} \cdot \frac{c_{\mathrm{b}} \cdot z_{\mathrm{b}, r} \cdot A_{r}^{z_{\mathrm{b}, r}-1}}{c_{\mathrm{b}} \cdot A_{r}^{z_{\mathrm{b}, r}}} \cdot A_{r} \cdot t=z_{\mathrm{b}, r} \cdot A_{\mathrm{o}} \cdot t$

The $\mathrm{CF}$ for regional effect I $\left(\mathrm{CF}_{\text {regI }}\right)$ equals to:

$\mathrm{CF}_{\text {regI }}=z_{\mathrm{b}, r}$

Regional effect II is calculated using the same approach as described by Eq. (7) and (8), but considering an enlargement taking place what results in a negative damage score. The regional $\mathrm{CF}\left(\mathrm{CF}_{\text {regI+III }}\right)$, when considering both effects, is given by:

$\mathrm{CF}_{\text {regI }+\mathrm{II}}=z_{\mathrm{b}, r}-z_{i, r}$

with $z_{\mathrm{b}, r}$ and $z_{i, r}$ the species accumulation factor of the baseline land and land use type $i$, on the regional scale $r$.

\subsection{Implementation}

\subsubsection{Land use types and management practices}

The dataset used in the study is the Countryside Survey 2000 (Defra 2000). The survey gathered vascular plant species data within Great Britain in 1998 by detailed field observations in randomly selected 1-km squares. Altogether, 569 sample squares were visited, which contain over 18,000 vegetation plots. For each vegetation plot, the corresponding land use type and vascular plant species number was collected and, depending on the location, 
classified into a specific broad habitat (Smart et al. 2003). We derived median species richness per land use type and calculated the $95 \%$ confidence level with the standard error (Table 1). The land use types arable land, fertile grassland, infertile grassland, moorland grass, and tall grassland were considered to be man-made and included in this paper. The land use type "upland wooded" was considered the most natural woodland type and therefore used as baseline. An overview of the different land use types, plot types, amount of vegetation plots, and the percentage of plots located in each broad habitat is listed in the Supporting Information (Table S1). A description of the land use types and broad habitats can be found in Table S2.

The Countryside Survey 2000 (Defra 2000) presents species richness figures for three types of land use plots: (1) the species richness of the field core, (2) the species richness at the inner margin, and (3) the species richness within the crop edge. Based on the fact that the species richness on arable land is strongly influenced by land use intensiveness (Wilson et al. 1999) and crop edges can act as refuge for species disappearing on the crop field (Fried et al. 2009), we linked the species richness of the three different plot types to three types of land use intensiveness using the CORINE land-cover classification (EEA 1995). We assumed that the species richness of field cores corresponds with intensive fields without edges, the species richness of inner field margins corresponds with less intensive used areas that contain only small borders and the species richness of field edges corresponds with organic arable areas with plenty of edges and small natural plots.

\subsubsection{Species accumulation factor $z$}

The species accumulation factor $\mathrm{z}$ is required to calculate the species richness factor c (Eq. 4) and the local and regional CFs (Eqs. 5 and 7). In this paper, the calculations were done by using (1) variable $z$ values as derived by Crawley and Harral (2001) and (2) a constant $z$ value of 0.25 (Crawley and Harral 2001). The variable $z$ values are land use type-specific and applied to spatial scales ranging from 10 to $10,000 \mathrm{~m}^{2}$ (Fig. 1). For arable land, variable $z$ values were available for a spatial scale of 100 to $200 \mathrm{~m}^{2}$ only. The variable $z$ values used to calculate the $c$ values and CFs for each land use type are presented in the Table S3 of the Supporting Information.

\subsubsection{Species richness factor $c$}

The species richness factors of the baseline and occupied land use type are required in the calculation of the local CF (Eq. 5). For each land use type, two versions of the $c$ value were derived by applying Eq. 4, using a species accumulation
Table 1 Land use type-specific values for species richness factor c, calculated with variable (var.) values for species accumulation factor $\mathrm{z}$ (hierarchic and egalitarian perspective) and a constant (const.) $z$ value of 0.25 (individualistic perspective). The area sizes and median species numbers derive from Defra (2000)

\begin{tabular}{|c|c|c|c|c|c|c|c|c|}
\hline \multirow[t]{2}{*}{ Land use type } & \multirow[t]{2}{*}{ Number of plots ${ }^{\mathrm{a}}$} & \multirow[t]{2}{*}{ Plot size $\left(\mathrm{m}^{2}\right)$} & \multicolumn{2}{|c|}{ Species number } & \multicolumn{2}{|c|}{$\begin{array}{l}c \text { value with var. } z \\
\text { values }\end{array}$} & \multicolumn{2}{|c|}{$\begin{array}{l}c \text { value with const. } z \\
\text { value }\end{array}$} \\
\hline & & & Median & $95 \% \mathrm{CL}$ & Median & $95 \% \mathrm{CL}$ & Median & $95 \% \mathrm{CL}$ \\
\hline Organic arable land & 26 & 10 & 7.3 & $5.8-9.1$ & & & 4.1 & $3.2-5.3$ \\
\hline Less intensive arable land ${ }^{\mathrm{b}}$ & 206 & 100 & 11.4 & $11.0-11.9$ & & & 3.6 & $2.8-4.6$ \\
\hline Intensive arable land ${ }^{\mathrm{b}}$ & 465 & 200 & 5.1 & $4.8-5.4$ & & & 1.4 & $1.0-1.8$ \\
\hline Organic fertile grassland & 212 & 10 & 11.5 & $10.8-12.2$ & 8.1 & $7.5-8.7$ & 6.5 & $5.6-7.3$ \\
\hline Less intensive fertile grassland & 33 & 100 & 13.1 & $10.5-16.1$ & 5.0 & $3.9-6.4$ & 4.1 & $3.0-5.8$ \\
\hline Intensive fertile grassland & 445 & 200 & 8.6 & $8.0-9.2$ & 3.2 & $2.9-3.6$ & 2.3 & $1.7-3.0$ \\
\hline Organic infertile grassland & 353 & 10 & 15.2 & $14.5-16.0$ & 10.8 & $10.1-11.4$ & 8.5 & $7.6-9.7$ \\
\hline Intensive infertile grassland & 458 & 200 & 19.1 & $18.3-19.9$ & 7.2 & $6.5-8.0$ & 5.1 & $3.9-6.7$ \\
\hline Organic moorland grass & 63 & 10 & 12.0 & $10.1-14.2$ & 9.1 & $7.7-10.8$ & 6.8 & $5.5-8.2$ \\
\hline Intensive moorland grass & 366 & 200 & 18.5 & $17.5-19.6$ & 5.6 & $4.9-6.4$ & 4.9 & $3.7-6.4$ \\
\hline Organic tall grassland & 646 & 10 & 10.9 & $10.6-11.2$ & 7.8 & $7.4-8.1$ & 6.2 & $5.4-7.0$ \\
\hline Less intensive tall grassland & 253 & 100 & 11.4 & $10.9-11.9$ & 4.4 & $4.0-4.9$ & 3.6 & $2.9-4.5$ \\
\hline Intensive tall grassland & 125 & 200 & 7.3 & $6.3-8.4$ & 2.8 & $2.3-3.3$ & 2.0 & $1.4-2.7$ \\
\hline Intensive woodland & 206 & 200 & 10.8 & $9.9-11.7$ & 1.1 & $0.8-1.4$ & 2.9 & $2.2-3.8$ \\
\hline Base: semi-natural woodland & 41 & 10 & 11.4 & $9.8-13.3$ & 6.6 & $5.6-7.6$ & 6.5 & $5.3-7.8$ \\
\hline
\end{tabular}

${ }^{a}$ Number of plots used to calculate the median species number and $95 \%$ confidence level of the average species number

${ }^{\mathrm{b}}$ No $z$ value presented by Crawley and Harral (2001); a $z$ value for field crops of $100 \mathrm{~m}^{2}$ is taken from Manhoudt et al. (2005) 
Fig. 1 Scale and land use type dependency of the species area relationship. The $z$ value determines the slope of the curve. With a log-log presentation, a constant $z$ value results in a straight line, while scale-dependent $z$ values results in area-specific slopes. Data derived from Crawley and Harral (2001)

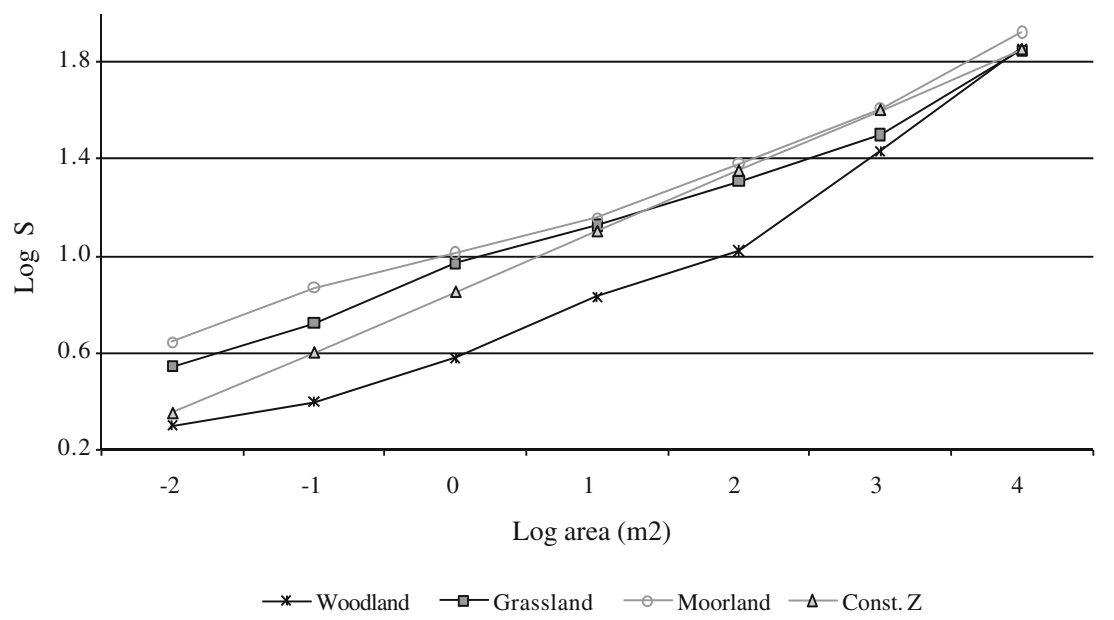

factor $\mathrm{z}$ corresponding to the respectively area size of the surveyed plot (variable $z$ ) and a constant $z$ value of 0.25 (Crawley and Harral 2001). The size of the survey area and the counted species numbers are given by the Countryside Survey 2000 dataset (Defra 2000). Table 1 presents, per land use type and plot type, the $c$ values for a constant and variable $z$ value.

\subsubsection{Perspectives}

To handle value choices in a consistent way, the Cultural Theory can be applied (Thompson et al. 1990; Hofstetter 1998). Three cultural perspectives are generally used, i.e., the individualistic, the egalitarian, and the hierarchist perspective (Goedkoop and Spriensma 1999; Goedkoop et al. 2008). The individualist coincides with the view that mankind has a high adaptive capacity through technological and economic development, and only proven effects should be considered. The egalitarian coincides with the view that nature is strictly accountable and precaution is required. The hierarchical perspective coincides with the view that impacts can be avoided with proper management and that the choice on what to include in the model is based on the level of (scientific) consensus. Table 2 gives an overview of the value choices included in our study and how we link them to the three perspectives we refer to in the discussion.

Table 2 Combination modeling choices and uncertainty for the species accumulation factor $\mathrm{z}$ and the regional effect, expressed in three different cultural perspectives

\begin{tabular}{|c|c|c|c|}
\hline Value choice & Individualist & Hierarchist & Egalitarian \\
\hline $\begin{array}{l}\text { Species } \\
\text { accumulation } \\
\text { factor } \mathrm{z}\end{array}$ & $\begin{array}{l}\text { Constant } z \\
\text { value of } \\
0.25\end{array}$ & $\begin{array}{l}\text { Variable } z \\
\quad\left(10,000 \mathrm{~m}^{2}\right)\end{array}$ & $\begin{array}{l}\text { Variable } z \\
\quad\left(10,000 \mathrm{~m}^{2}\right)\end{array}$ \\
\hline $\begin{array}{l}\text { Regional } \\
\text { effect }\end{array}$ & $\begin{array}{l}\text { No regional } \\
\text { effect }\end{array}$ & $\begin{array}{l}\text { Regional } \\
\text { effect I+II }\end{array}$ & $\begin{array}{r}\text { Regional } \\
\text { effect I }\end{array}$ \\
\hline
\end{tabular}

Dependency of the $z$ value towards land use type and area size is widely acknowledged in the literature on species area relationships (e.g., Rosenzweig 1995; Crawley and Harral 2001). Therefore, we considered a variable $z$ value for the hierarchist and egalitarian perspective. An area size of $10,000 \mathrm{~m}^{2}$ is used, as this is largest available in the dataset. The use of a constant $z$ value is a simplification of the model what makes it more robust, independent of the life cycle inventory data, and is assumed for the individualist perspective. A second value choice relates to the inclusion of the regional effect I and II. The regional effects are zero when a constant $z$ value is used (see Eq. 10) and therefore not applicable for the individualist perspective. The egalitarian perspective followed worst case scenario what coincides with excluding environmental benefits and thus regional effect II, while the hierarchist included both regional effects I and II.

\subsubsection{Monte Carlo simulation}

The parameter uncertainty within the CFs derives from both the uncertainty in $c$ values and $z$ values. For the $c$ values, a $t$-distribution for the uncertainty in species number was applied, and standard deviations were derived from the Countryside Survey 2000 (Defra 2000). For the species accumulation factor $\mathrm{z}$, a bounded normal uncertainty distribution (ranging from 0 to 1 ) was used. The uncertainty in area-dependent $z$ values was quantified with a coefficient of variation of 0.05 (Crawley and Harral 2001). A constant $z$ value was assumed to have a higher uncertainty (coefficient of variation of 0.1 ) due to the relative high variation in generic $z$ values reported in the literature. Monte Carlo simulations were performed in crystal ball (Crystal ball 1998), applying 10,000 iterations for each simulation.

The difference between CFs was statistically tested by taking the covariance between the CFs into account in the 
Monte Carlo simulation. Depending on the perspective, covariance in the CFs can occur due to equal species accumulation factors $\mathrm{z}$ and an equal baseline land use type (see Table 1, S3 and S4). For instance, in the individualistic perspective, the constant $z$ value was varied simultaneously for all land use types, as we assume in this case the same $z$ value for all land use types and practices included. For the hierarchic and egalitarian perspective, the same is true for the regional $z$ value of the baseline land use "semi-natural woodland" and the $z$ value of the different grassland land use types, which were simultaneously varied. The covariance in the CFs was accounted for by calculating the difference between pairs of $\mathrm{CFs}$ in the Monte Carlo simulations. If the difference between the pair of CFs was in $>95 \%$ of the runs negative or positive, we consider the CFs to be significantly different from each other $(\alpha=0.1$, two-sided confidence interval).

\section{Results}

Table 3 shows the CFs for the individualist, hierarchist, and egalitarian perspective. For arable land, $z$ values for a spatial scale of $10,000 \mathrm{~m}^{2}$ were not available, preventing the calculation of CFs for arable land within the hierarchist and egalitarian perspective. Independent from the perspective chosen, we observe that intensive land use practice has the highest $\mathrm{CF}$, followed by less intensive and organic land use practice of each land use type (see Table 3, S5, S6 and S7). Note that the occupation of land can result in a combination of both local and regional effects, and therefore the total CF (and PDF value) can become higher than one as referred to the land occupation.

We observe that the absolute values of the CFs differ depending on the perspective chosen. The individualist and egalitarian perspective present the lower and upper range of the three perspectives, respectively, with an average difference of $0.8 \mathrm{PDF}$ and a maximum difference of 1.05 $\mathrm{PDF}$, i.e., the $\mathrm{CF}$ of organic infertile grassland varies from -0.33 PDF for the individualist perspective to 0.72 PDF for the egalitarian perspective. The hierarchist perspective falls between the individualist and egalitarian perspective. The median CFs for the hierarchist perspective (including regional effect I+II) range from 0.37 to $0.91 \mathrm{PDF}$ for the land use types other than the baseline. Compared with the hierarchist perspective, the exclusion of regional effect II within the egalitarian perspective results in CFs that are $32-44 \%$ higher (see Table S4 in the Supporting Information). When using a constant $z$ value, the individualist perspective always results in lower CFs, in some cases leading to negative median CFs.

The calculated parameter uncertainty results in an uncertainty range of on average $0.20 \mathrm{PDF}$ ( $95 \%$ confidence
Table 3 Characterisation factors (CFs) for the individualist, hierarchist, and egalitarian perspectives for six different land use types and three levels of land use intensiveness. The $95 \%$ confidence level (CL) is calculated using a $t$-distribution for the average species number $S$ (see Table 1) and a bounded normal uncertainty distribution for the species accumulation factor $\mathrm{Z}$

\begin{tabular}{|c|c|c|c|c|c|c|}
\hline \multirow[t]{2}{*}{ Land use types } & \multicolumn{2}{|c|}{$\mathrm{CF}$ individualist } & \multicolumn{2}{|c|}{ CF hierarchist } & \multicolumn{2}{|c|}{$\mathrm{CF}$ egalitarian } \\
\hline & Median & $95 \% \mathrm{CL}$ & Median & $95 \% \mathrm{CL}$ & Median & $95 \% \mathrm{CL}$ \\
\hline Organic arable land ${ }^{\mathrm{a}}$ & 0.36 & $0.15-0.51$ & & & & \\
\hline Less intensive arable land ${ }^{\mathrm{a}}$ & 0.44 & $0.31-0.54$ & & & & \\
\hline Intensive arable land $\mathrm{d}^{\mathrm{a}}$ & 0.79 & $0.73-0.83$ & & & & \\
\hline Organic fertile grassland & -0.01 & $-0.18-0.15$ & 0.55 & $0.13-0.83$ & 0.90 & $0.49-1.16$ \\
\hline Less intensive fertile grassland & 0.36 & $0.14-0.52$ & 0.75 & $0.45-0.95$ & 1.10 & $0.82-1.29$ \\
\hline Intensive fertile grassland & 0.65 & $0.56-0.72$ & 0.87 & $0.68-1.02$ & 1.22 & $1.04-1.35$ \\
\hline Organic infertile grassland & -0.33 & $-0.56-0.13$ & 0.37 & $-0.17-0.72$ & 0.72 & $0.20-1.05$ \\
\hline Intensive infertile grassland & 0.21 & $0.02-0.37$ & 0.61 & $0.22-0.86$ & 0.96 & $0.59-1.19$ \\
\hline Organic moorland grass & -0.05 & $-0.32-0.16$ & 0.65 & $0.28-0.90$ & 0.97 & $0.62-1.21$ \\
\hline Intensive moorland grass & 0.23 & $0.04-0.39$ & 0.83 & $0.59-1.00$ & 1.15 & $0.93-1.31$ \\
\hline Organic tall grassland & 0.04 & $-0.12-0.18$ & 0.58 & $0.17-0.84$ & 0.93 & $0.54-1.17$ \\
\hline Less intensive tall grassland & 0.44 & $0.32-0.54$ & 0.80 & $0.54-0.97$ & 1.15 & $0.91-1.30$ \\
\hline Intensive tall grassland & 0.70 & $0.61-0.77$ & 0.91 & $0.72-1.04$ & 1.25 & $1.09-1.37$ \\
\hline Intensive woodland & 0.55 & $0.44-0.65$ & 0.84 & $0.78-0.88$ & 1.28 & $1.21-1.34$ \\
\hline Baseline: semi-natural woodland & 0.00 & & 0.00 & & $0.00^{\mathrm{b}}$ & \\
\hline
\end{tabular}

${ }^{\mathrm{a}}$ No $z$ value presented by Crawley and Harral (2001)

${ }^{\mathrm{b}}$ For the baseline, considering regional effect I is always in combination with regional effect II 
interval) for land use types other than the baseline and vary between 0.04 and 0.54 PDF (see Table 3). For the hierarchist and egalitarian perspective, the uncertainty derives for more than $85 \%$ from the regional variable $z$ values, while the parameter uncertainty in median species numbers per land use type mainly clarifies the uncertainty within the individualist perspective. Accounting for the positive covariance between the CFs of the various land use types, we found that, for the individualist perspective, $85 \%$ of the CFs are significantly different, while for the egalitarian and hierarchist perspective, respectively $68 \%$ to $80 \%$ of the CFs are significantly different $(\alpha=0.1$, twosided confidence interval). Tables S5, S6, and S7 in the Supporting Information present for each perspective a matrix of ranked land use types (sorted constitutively from small to large $\mathrm{CFs}$ ), together with the corresponding confidence levels of the difference in CFs.

\section{Discussion}

Within the calculations of the CFs for 15 different land use types, the sensitivity towards the $z$ values and regional effects in the damage model was analyzed. The effects of land occupation was quantified as disappeared fraction of species to allow aggregation of land use damage with other ecosystem impacts such as climate change (De Schryver et al. 2009). Value choices in the damage model were assessed by establishing three scenarios following the Cultural Theory (Thompson et al. 1990; Hofstetter, 1998), and parameter uncertainty was quantified through Monte Carlo simulation.

\subsection{Perspectives}

The results show that, independent of the perspective, the intensive land use practice has the highest $\mathrm{CF}$, followed by less intensive and organic land use practice of each land use type. However, the absolute values of the CFs can substantially differ, depending on the perspective chosen. The differences in results are caused by the choice of a generic or a land use-specific species accumulation factor $\mathrm{z}$, and the choice of including or excluding regional effects. The difference in CFs between the hierarchist and individualist perspective mainly derives from the choice in applying a variable or constant $z$ value and is land use type-specific. The choice of applying a constant $z$ value is a way of simplifying reality. The constant $z$ value can range from 0.12 for large human-induced areas to 1.00 or even more for isolated islands, depending on several factors, such as the level of isolation and diverse habitats (Humphreys and Kitchener 1982; Rosenzweig, 1995). Comparing the egalitarian and the hierarchist perspective, the difference in CFs is land use type-independent and determined by the choice to include or exclude regional effects.

For the hierarchist and egalitarian perspective, the baseline $z$ value is higher or equal to the $z$ value of land use type $i$. This result in positive CFs, even when the corresponding species richness factor $\mathrm{c}$ of land use type $i$ is higher than the $c$ value of the baseline. The individualist perspective applies a constant $z$ value, resulting in CFs that are determined by the difference in $c_{\mathrm{b}}$ and $c_{i}$. This is obviously also the case when the area-dependent $z$ values $z_{i}$ and $z_{\mathrm{b}}$ are approximately equal. Due to data limitations, this study only calculated CFs for an area size of $10,000 \mathrm{~m}^{2}$. For the land use type arable land, an area-dependent $z$ value for $10,000 \mathrm{~m}^{2}$ was not available, and thus CFs could not be calculated for the hierarchist and egalitarian perspective. An option for deriving area-dependent $z$ values per land use type could be by developing a mathematical relationship, mechanistic or empirical, between $z$ and area size. Such a mathematical relationship is readily available for the UK (Crawley and Harral 2001), although not further specified per land use type. Further research in deriving land usespecific general relationships between $z$ and area size would be of added value and could also be used to derive CFs for other area sizes than $10,000 \mathrm{~m}^{2}$.

In this study, the Cultural Theory is used a framework to develop different scenarios and with this to evaluate effects from different visions on including regional effects and the use of variable $z$ values. However, the developed scenarios are suggested default scenarios and can be adapted depending on the vision of the practitioner. Furthermore, other value choices could be implemented as well, such as the choice of baseline and the type of species to consider.

The choice of baseline may also influence our results and can be linked to cultural perspectives as well. In this study, we used "semi-natural woodland" as default baseline without considering alternative baseline settings. However, the average regional species richness (Koellner and Scholz 2008) and the maximum species richness (Lindeijer 2000; Weidema and Lindeijer 2001) are also proposed as a baseline for land use in LCA context. The species richness of our baseline "natural land" equals the average species number for Great Britain, which ranges from 5.0 to 7.5 species $/ \mathrm{m}^{2}$ (AFE 2001; Crawley and Harral 2001). The maximum species richness in our dataset is found on the land use type "organic infertile grassland", what corresponds to $8.5-10.8 \mathrm{species} / \mathrm{m}^{2}$ and a $z$ value of 0.35 instead of 0.44 . The lower $z$ value results in reduced $\mathrm{CFs}$ up to a factor of 2 , when using the maximum species richness in the egalitarian perspective. We did not consider the choice of a maximum baseline in our model scenarios as it falls outside the scope of our 
study. In case of applying the cultural perspectives, we suggest to use (1) the average regional species richness for the individualist perspective as this is most local, (2) "semi-natural" land for the hierarchist perspective as this is most consensus, and (3) the maximal species richness for the egalitarian perspective who believes any land occupation is damaging.

Another aspect that can be linked to the perspectives is the inclusion of threatened species or all species in the calculation of CFs (De Schryver et al. 2009). For instance, Koellner and Scholz (2008) provide information on the effect of land use on respectively all species and threatened species only. This allows differentiation between land use types with original species richness and species richness induced by human interference, for example natural woodland and artificial meadow. A subdivision in threatened species was not possible within our dataset, but is considered a relevant modeling step in a further specification of the perspectives.

\subsection{Parameter uncertainty}

The presented parameter uncertainty differs per perspective. For the individualist perspective, the parameter uncertainty only derives from uncertainty in the species richness factors $\mathrm{c}$ and is higher than the uncertainty from local damage for the hierarchist and egalitarian perspective. This is due to the higher uncertainty range for the constant $z$ value applied in the individualist perspective compared with the variable $z$ values for the other two perspectives. However, when adding the area dependency and regional damage, the parameter uncertainty of the total CFs for the hierarchist and egalitarian perspectives becomes higher than for the individualist perspective that excludes these effects. The exception is, however, for intensive woodland with zero regional effects in all perspectives because occupation with the same land use type as the baseline removes regional effects and excludes the area dependency due to the same $z$ values $\left(z_{i}\right.$ and $\left.z_{\mathrm{b}}\right)$ applied.

For the hierarchist and egalitarian perspective, the parameter uncertainty is for more than $80 \%$ explained by the uncertainty in the regional species accumulation factor z. However, the uncertainty in the applied $z$ value can be larger than presented when the choice in area size would be reflected in the parameter uncertainty instead of considered as modeling choice.

Within each model scenario, the CFs of the different land use types do not always significantly differ. On average, two to four land use types with consecutive CFs do not significantly differ. The individualist shows the highest number of CFs which significantly differ due to the covariance in the applied constant $z$ value.

\subsection{Model uncertainty}

Apart from model choices and parameter uncertainty, model uncertainties can also influence the outcomes of the study. First of all, land use CFs are highly regiondependent. The use of data from Great Britain makes the results inapplicable on a global scale, but still adequate to analyze different model uncertainties, as done in this study. Second, it is important to note that the use of variable $z$ values requires the size of land area under study. This is not always known in LCA, what includes extra
Fig. 2 Characterisation factors (CFs) for the three cultural perspectives and the local $\mathrm{CFs}$ of Koellner and Scholz (2008), for seven land use types. The error bars indicate the $95 \%$ confidence level (CL) calculated by using a $t$-distribution for the average species number $S$ and a bounded normal uncertainty distribution (ranging from 0 to 1) for the species accumulation factor z. Note that no CFs are presented for arable land when using a hierarchist or egalitarian perspective, as for this land use type, no variable $z$ values were found

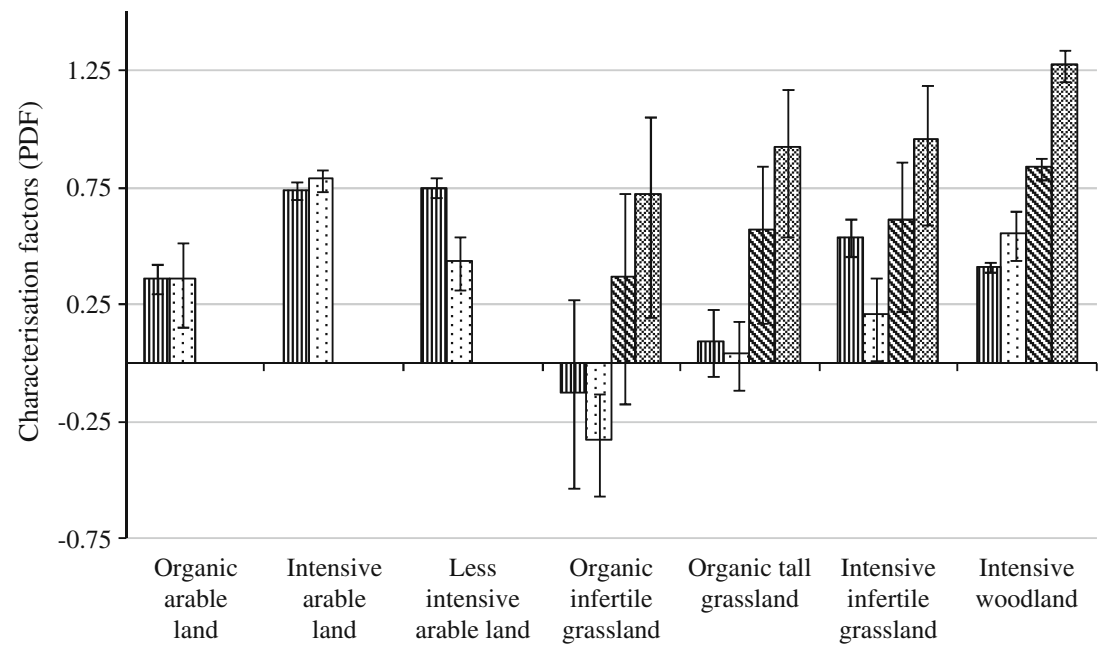

mKoellner 2008 口Individualist \$Hierarchist @Egalitairian 
model uncertainty and can largely influence the outcome of the CF. Third, within the formulas $A_{r}-A_{\mathrm{o}} \approx A_{r}$ and $A_{i}+A_{\mathrm{o}} \approx A_{i}$, we assumed the newly occupied area $A_{\mathrm{o}}$ to be small compared with the size of the region. When the occupied area $A_{\mathrm{o}}$ is less than $1 \%$ of both $A_{r}$ and $A_{i}$, the total regional effect $\left(\mathrm{CF}_{\text {regI+II }}\right)$ only marginally increases, i.e., $<5 \%$ of the regional PDF. Fourth, our assumption of field edges, representing the amount of species present on low intensive or organic fields, is debatable. Hald (1999) compared the species density of field margins with field centers for both organic and conventional farming. This research indicates that the species density of field margins of organic farming is representative for the whole field while the species density of the field center of conventional fields is $30-40 \%$ lower than of the field margins (Hald 1999). While it is generally recognized that organic farming has positive effects on the species richness compared with conventional farming, in some cases, field studies indicate negative or mixed effects (Hole et al. 2005). Hole et al. (2005) analyzed 76 comparative studies on organic and conventional farming and indentified three broad management options largely used (but not exclusive) in organic farming and assumed to be mainly advantageous to biodiversity: (1) prohibition/ reduced use of chemical pesticides and inorganic fertilizers; (2) establishment of non-crop habitats and field margins; and (3) preservation of mixed farming (i.e., arable fields in close juxtaposition with pastoral elements). This indicates that focusing on field margins alone is not sufficient to define land use intensiveness. We suggest the inclusion of mixed farming together with pesticides and fertilizer use as two extra indicators on both inventory and impact assessment level to better assess the impact on biodiversity due to land use intensiveness.

\subsection{Comparison with other life cycle impact assessment methods}

In Fig. 2, we compare our CFs with the CFs of Koellner and Scholz (2008) representing all plant species. The CFs of the individualist perspective are closest to the CFs of Koellner and Scholz (2008), as for five out of the seven land use types the CFs differ less than 0.2 PDF and two land use types show a difference of 0.3 PDF. The choice of a fixed $z$ value and excluding regional effects, as employed in the individualist perspective, corresponds with the modeling approach of Koellner and Scholz (2008). For the other two perspectives, the differences are larger, i.e., up to 0.50 PDF for the hierarchist and $0.87 \mathrm{PDF}$ for the egalitarian perspective. Note that Koellner and Scholz (2008) also present parameter uncertainties but solely deriving from uncertainty in species number and therefore smaller than the uncertainties presented in our study.

\section{Conclusion and recommendations}

We analyzed the uncertainties in the species area relationship and how they influence the CFs of various land use types. Three scenarios are used to handle the different modeling choices. It is found that the ranking of organic, less intensive, and intensive land practices of each land use type is not affected by the chosen model scenario. The absolute values of the CFs are highly dependent on the modeling choices within the species area relationship. Applying a constant $z$ value and excluding regional effects results in $\mathrm{CFs}$ which are in the lower range of our results and can even turn negative. The use of a variable $z$ value and including regional effects results in higher CFs. Depending of the chosen scenario, the calculated parameter uncertainty derives mainly from the uncertainty in the variable $z$ value or the uncertainty in average species numbers. Within each model scenario, the majority of the CFs $(68 \%$ to $85 \%)$ significantly differs from each other. Decreasing the parameter uncertainty, particularly in the species accumulation factor $\mathrm{z}$, could further increase the number of significantly different CFs. We consider the use of variable $z$ values as preferable, although the use of $\mathrm{CFs}$ on the basis of variable $z$ value may not always be feasible due to the user knowledge of the actual area size of the land occupied and the available land use-specific $z$ values. More research towards the development of land usespecific general relationships between $z$ value and area size is needed.

Acknowledgement This work is part of the ReCiPe project and was financed by the Ministry of Housing, Spatial Planning, and Environment.

Open Access This article is distributed under the terms of the Creative Commons Attribution Noncommercial License which permits any noncommercial use, distribution, and reproduction in any medium, provided the original author(s) and source are credited.

\section{References}

AFE (2001) Atlas Florae Europaeae. Botanical museum of the Finnish Museum of Natural History. Available at: http:// www.luomus.fi/english/botany/afe/publishing/summary.htm. Accessed on: 2009

Baitz M, Kreissig J, Schöch C (1998) Methode zur Integration der Naturraum-Inanspruchnahme in Ökobilanzen. Universität Stuttgart, Stuttgart

Bos U, Wittstock B (2008) Integration of land use effects into LCA: Documentation of methodological approach and operationalisation to describe land use effects in life cycle assessment. Version 2 working document, under continuous revision. LeinfeldenEchterdingen, Universität Stuttgart, Chair of Building Physics, Department Life Cycle Engineering

Collins MD, Vazquez DP, Sanders NJ (2002) Species area curves, homogenization and the loss of global diversity. Evol Ecol Res 4 (3):457-464

Crawley MJ, Harral JE (2001) Scale dependence in plant biodiversity. Science 291:864-868 
Crystal ball (1998) Forecasting and risk analysis for spreadsheet users. Denver, Decisioneering

De Schryver AM, Brakkee KW, Goedkoop MJ, Huijbregts MAJ (2009) Characterization factors for global warming in life cycle assessment based on damages to humans and ecosystems. Environ Sci Technol 43:1689-1695

Defra (2000) Countryside Survey 2000. Department for Environment, Food and Rural Affairs. Available at: www.countrysidesurvey. org.uk. Accessed on: 2009

Dolnik C, Breuer M (2008) Scale dependency in the species-area relationship of plant communities. Folia Geobot 43:305-318

EEA (1995) CORINE Land Cover. European Environmental Agency. Available at: http://reports.eea.europa.eu/COR0-landcover/en. Accessed on: 2009

FAO (2000) Global Agro-ecological zones Food and Agriculture Organization. Available at: www.fao.org/ag/agl/agll/gaez/index. htm. Accessed on: 2009

Fried G, Petit S, Dessaint F, Reboud X (2009) Arable weed decline in Northern France: crop edges as refugia for weed conservation? Biol Conserv 142:238-243

Goedkoop M, Spriensma RT (1999) The eco-indicator 99: a damage oriented method for life cycle impact assessment methodology. PRé Consultants, Amersfoort

Goedkoop M, Heijungs R, Huijbregts M, De Schryver A M, Struijs J, Van Zelm R (2008) ReCiPe 2008. A life cycle impact assessment method which comprises harmonised category indicators at the midpoint and the endpoint level; First edition Report I. Characterisation. Den Haag, VROM, 133

Hald AB (1999) Weed vegetation (wild flora) of long established organic versus conventional cereal fields in Denmark. Ann Appl Biol 134:307-314

Hannus JJ, von Numers M (2008) Vascular plant species richness in relation to habitat diversity and island area in the Finnish Archipelago. J Biogeogr 35:1077-1086

Harner RF, Harper KT (1976) Role of area, heterogeneity, and favorability in plant species-diversity of pinyon-juniper ecosystems. Ecology 57:1254-1263

Hofstetter P (ed) (1998) Perspectives in life cycle impact assessment. A structured approach to combine models of the technosphere, ecosphere and valuesphere. Kluwer Academic Publishers, Dordrecht

Hole DG, Perkins AJ, Wilson JD, Alexander IH, Grice PV, Evans AD (2005) Does organic farming benefit biodiversity? Biol Conserv 122:113-130

Humphreys WF, Kitchener DJ (1982) The effect of habitat utilization on species-area curves: implications for optimal reserve area. J Biogeogr 9:391-396

Jeanneret P, Baumgartner D, Freiermuth R, Gaillard G (2006) Life cycle impact assessment method for the impact of agricultural activities on biodiversity. Agroscope FAL Reckenholz 53

Kallimanis AS, Mazaris AD, Tzanopoulos J, Halley JM, Pantis JD, Sgardelis SP (2008) How does habitat diversity affect the species-area relationship? Glob Ecol Biogeogr 17:532-538

Koellner T (2000) Species-pool effect potentials (SPEP) as a yardstick to evaluate land-use impacts on biodiversity. J Clean Prod 8:293-311

Koellner T, Scholz R (2007) Assessment of land use impacts on the natural environment. Part 1: an analytical framework for pure land occupation and land use change. Int J Life Cycle Assess 12:16-23

Koellner T, Scholz R (2008) Assessment of land use impacts on the natural environment. Part 2: generic characterization factors for local species diversity in Central Europe. Int J Life Cycle Assess 13:32-48

Lindeijer E (2000) Biodiversity and life support impacts of land use in LCA. J Clean Prod 8:313-319

Lomolino W (2001) Towards a more general species area relationship: diversity on all islands, great and small. J Biogeogr 28:431-445
Losos JB, Schluter D (2000) Analysis of an evolutionary species-area relationship. Nature 408:847-850

MacArthur RH, Wilson EO (eds) (1967) The theory of island biogeography, New Jersey. Princeton University Press, Princeton

Manhoudt AGE, Udo de Haes HA, de Snoo GR (2005) An indicator of plant species richness of semi-natural habitats and crops on arable farms. Agricult Ecosys Environ 109:166-174

Mattsson B, Cederberg C, Blix L (2000) Agricultural land use in life cycle assessment (LCA): case studies of three vegetable oil crops. J Clean Prod 8:283-292

Milà i Canals L, Dubreuil A, Gaillard G, Müller-Wenk R (2007a) Key elements in a framework for land use impact asessment within LCA. Int J Life Cycle Assess 12:5-15

Milà i Canals L, Romanyà J, Cowell SJ (2007b) Method for assessing impacts on life support functions (LSF) related to the use of 'fertile land' in life cycle assessment (LCA). J Clean Prod 15:1426-1440

Muller-Wenk R (1998) Land use - the main threat to species. How to include land use in LCA. Universität St. Gallen, St. Gallen, Switzerland, IWÖ Diskussionsbeitrag no. 64

Oberholzer H-R, Weisskopf P, Gaillard G, Fr FW, Freiermuth R (2006) Life cycle impact assessment method for the impact of agricultural activities on soil quality. Agroscope FAL Reckenholz, Bern, Switzerland, 58

Rosenzweig ML (ed) (1995) Species diversity in space and time. Cambridge University Press, Cambridge

Sala OE, Chapin FS III, Armesto JJ, Berlow E, Bloomfield J, Dirzo R, Huber-Sanwald E, Huenneke LF, Jackson RB, Kinzig A, Leemans R, Lodge DM, Mooney HA, Oesterheld M, Poff NL, Sykes MT, Walker BH, Walker M, Wall DH (2000) Global biodiversity scenarios for the year 2100 . Science 287:1770-1774

Sarukhán J, Whyte A, Board M (eds) (2005) Ecosystems and human well-being: biodiversity synthesis, Washington. World Resources Institute, $\mathrm{DC}$

Schmidt JH (2008) Development of LCIA characterisation factors for land use impacts on biodiversity. J Clean Prod 16:1929-1942

Sleeswijk WA, Kleijn R, van Zeijts H, Reus JAWA, van Omna MJG, Leneman H, Sengers HHWJM (1996) Application of LCA to agricultural products: 1 . Methodological keypoints; 2 . Adds on to the 'Guidline for LCA'; 3. Methodological backgrounds. Den Haag, CML, Centrum voor Landbouw en Milieu, LandbouwEconomisch Instituut (LEI-DLO), 119

Smart SM, Clarke RT, van de Poll HM, Robertson EJ, Shield ER, Bunce RGH, Maskell LC (2003) National-scale vegetation change across Britain; an analysis of sample-based surveillance data from the countryside surveys of 1990 and 1998. J Environ Manag 67:239-254

Stanners D, Philippe B (1995) Europe's environment-the Dobris assessment. European Environment Agency, Copenhagen

Thompson M, Ellis R, Wildavsky A (1990) Cultural theory. Westview Press, Boulder

Vogtlander JG, Lindeijer E, Witte JPM, Hendriks C (2004) Characterizing the change of land-use based on flora: application for EIA and LCA. J Clean Prod 12:47-57

Wagendorp T, Gulinck H, Coppin P, Muys B (2006) Land use impact evaluation in life cycle assessment based on ecosystem thermodynamics. Energy 31:112-125

Weidema B, Lindeijer E (2001) Physical impacts of land use in product life cycle assessment. Final report of the EURENVIRONLCAGAPS sub-project on land use. Denmark, Department of Manufacturing Engineering and Management, Technical University

Wilson JD, Morris AJ, Arroyo BE, Clark SC, Bradbury RB (1999) A review of the abundance and diversity of invertebrate and plant foods of granivorous birds in northern Europe in relation to agricultural change. Agricult Ecosys Environ 75:13-30 